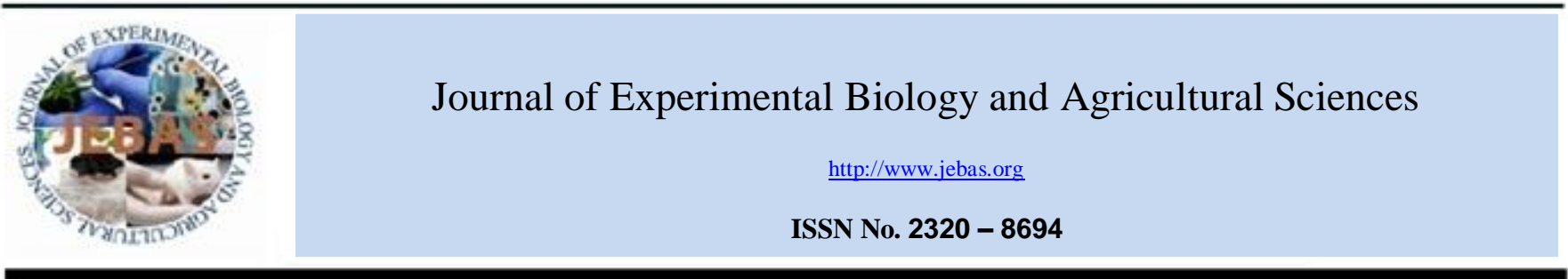

\title{
MOLECULAR IDENTIFICATION AND CHARACTERIZATION OF DIFFERENT DENGUE VIRUS SEROTYPES REPORTED IN JAZAN AREA, KINGDOM OF SAUDI ARABIA
}

\author{
Abdulaziz M. Hakami ${ }^{1 *}$, Mohammed I. Qadri ${ }^{1}$, Khalid Al-Ghamdi ${ }^{1}$, Naser A. Alkenani ${ }^{1}$, \\ Zaki Monawar Eisa ${ }^{2}$, Abdullatif M. Matabi ${ }^{2}$, Marwah Bakri. ${ }^{3}$
}

${ }^{1}$ Department of Biological Science, King Abdulaziz University, Jeddah, Saudi Arabia.

${ }^{2}$ King Fahd Hospital, Jazan, Saudi Arabia.

${ }^{3}$ Jazan University, Jazan, Saudi Arabia.

Received - August 23, 2018; Revision - September 21, 2018; Accepted - October 01, 2018

Available Online - October 5, 2018

DOI: http://dx.doi.org/10.18006/2018.6(5).828.835

\author{
KEYWORDS \\ Dengue virus \\ Reverse Transcriptase \\ Polymerase Chain Reaction \\ Jazan \\ Saudi Arabia
}

* Corresponding author

E-mail: ahakami@ outlook.com (Abdulaziz M. Hakami)

Peer review under responsibility of Journal of Experimental Biology and Agricultural Sciences.

Production and Hosting by Horizon Publisher India [HPI] (http://www.horizonpublisherindia.in/).

All rights reserved.

\begin{abstract}
Dengue virus (DENV) is the public health threat worldwide. In fact, since 1994, Kingdome of Saudi Arabia (KSA) was reported dengue-free country. Later, outbreaks have been reported in Jeddah and Makkah and the dissemination of new DENV strains and serotypes into different localities could be attributed to the annual displacement of pilgrims from dengue endemic regions. Therefore, early detection of multiple infections is a crucial factor for patient's hospitalization and symptomatic treatment. The objective of the current study was to detect, characterize and to analyse the magnitude of concurrent DENV infection in Jazan area as base data for future control strategies. A total of 123 blood samples from febrile patients at Jazan area were collected. Viral RNA was subjected to Reverse Transcriptase Polymerase Chain Reaction (RT-PCR) and nested PCR. Dengue virus RNA from 12 RTPCR positive blood samples was extracted, purified, the all viral genome sequenced, and their nucleotide sequences were searched for similarity in the GenBank. The RT-PCR results of 123 tested samples, showed $79(64.2 \%)$ DENV positive while $44(35.8 \%)$ are negative. DENV1 was detected in 63 out of 79 samples $(79.7 \%)$ followed by DENV2 $(13 / 79=16.5 \%)$, and concurrent mixed infection with both DENV1 and DENV2 $(3 / 79=3.8 \%)$, but DENV3 and DENV4 were not detected in all tested samples. Concurrent mixed infection with multiple DENV serotypes (DENV1, DENV2) was detected for the first time in Jazan area, KSA.
\end{abstract}

All the article published by Journal of Experimental Biology and Agricultural Sciences is licensed under a Creative Commons Attribution-NonCommercial 4.0 International License Based on a work at www.jebas.org.

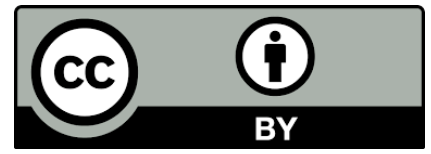




\section{Introduction}

Dengue virus (DENV) is the most common arthropod-borne viral disease, causes a substantial public health burden (Guzman et al., 2010). Disease has different forms including dengue fever, dengue hemorrhagic fever and dengue shock syndrome (Whitehead et al., 2007; Varatharaj, 2010). The disease severities are range from undifferentiated acute febrile illness to the life-threatening conditions (Gubler, 2002). The virus is a single strand RNA virus with 4 (DENV 1 to 4) genetically distinct groups known as serotypes (de Alwis et al., 2011) and is transmitted to human by Aedes aegypti mosquitoes (Lambrechts et al., 2010). Many factors (temperature, rainfall, humidity, air travel, topographic societal, insecticides resistance and impact of ecology) (Alto \& Juliano, 2001; Armstrong \& Rico-Hesse, 2003; Simard et al., 2005; Chan \& Johansson, 2012) are responsible for increased disease incidence and sustainable transmission in many countries including Kingdom of Saudi Arabia (KSA). In fact, since 1994, KSA was reported denguefree country (Ashshi, 2015). Later, outbreaks have been reported in Jeddah and Makkah and the dissemination of new DENV strains and serotypes into different localities could be attributed to the annual displacement of pilgrims from dengue endemic regions (Ashshi, 2015; Azhar et al., 2015; Ashshi, 2017; Organji et al., 2017). Worldwide, concurrent mixed infection with multiple DENV serotypes is considered as alarm signs of the large dispersal of different DENV serotypes resulting in dengue complicated cases (WHO, 2014), and co-infected patients are skewed towards more severe clinical manifestations compared to mono-infected patients (Dhanoa et al., 2016) and the occurrence of co-infections rates are ranging from 5-30\% (Martins et al., 2014), from 40-50 \% (Vinodkumar et al., 2013), and recently very high up to $100 \%$ mixed infections were reported in India (Reddy et al., 2017). To date, DENV severities, detection and characterization were not extensively studied in Jazan area, KSA. In this area, the virus was routinely diagnosed by serology; the results of these diagnostic techniques are less sensitive and non-specific to differentiate between the four viral serotypes infections. However, diagnosis of DENV concurrent mixed infections using molecular species-specific primers was effective diagnostic tool for serotyping and for early detection at field levels has a significant impact on the prediction and characterization for future control strategies. The objective of the current study was to detect, characterize and to analyse the magnitude of concurrent DENV infection in Jazan area as base data for future control strategies and to determine their genetic relatedness with other published sequences in the GenBank.

\section{Materials and methods}

\subsection{Study area}

Jazan Region, KSA is stretching out $300 \mathrm{~km}$ along the Southern Red Sea coast, covering an area of $11,671 \mathrm{~km}^{2}$ and is populated by 1533,680 . The area is characterized by a distinctive hot and humid climate, inadequate sewage and waste management systems provide important sides for mosquito breeding. In addition, the area attracts large number of visitors, and migrants, thus the dissemination of DENV in the area is expected.

\subsection{Ethical approval and informed consent:}

The research proposal was reviewed and accepted by the Research Ethic Committee, King Abdulaziz University. Ethical approval was obtained from Ministry of Health, Saudi Arabia. Before blood samples collection, the patient, parent, or guardian provided a written informed consent.

\subsection{Blood samples}

Five $\mathrm{ml}$ venous blood samples from 123 patients were aseptically taken from febrile patients admitted to 13 hospitals at Jazan area, KSA. Sera samples were processed by divided into two aliquots in screw-capped cryotubes (Greiner Bio-One, Germany) and were kept at $-80^{\circ} \mathrm{C}$ until use.

\subsection{RNA isolation}

High Pure Viral Nucleic Acid Kit (Roche Applied Science, Germany) was used for the extraction of RNA from all sera samples, following the manufacturer procedures with minor modifications. Briefly, in a nuclease-free $1.5 \mathrm{ml}$ microcentrifuge tube added $200 \mu \mathrm{l}$ of binding buffer, $50 \mu 1$ Proteinase $\mathrm{K}$ and 200 $\mu 1$ of serum sample, immediately mixed and were incubated for 10 minutes at $72^{\circ} \mathrm{C}$. To the mixture, extra $100 \mu$ Proteinase $\mathrm{K}$ was added, mixed and was transferred to High Filter Tube inserted into Collection Tube. After centrifugation for 1 minute at 10000 rpm, the collection tube was discarded. The filter tube combined with new collection tube and $500 \mu 1$ of inhibitor removal buffer was added and centrifuged for 1 minute at $10000 \mathrm{rpm}$. After changing collection tube, the high filter tube washed twice by adding $450 \mu \mathrm{l}$ of wash buffer at the same condition of centrifugation, followed by centrifugation for 15 seconds at 13000 rpm to remove any residual wash buffer. Then the high filter tube was inserted into nuclease free, sterile $1.5 \mathrm{ml}$ centrifuge tube and $50 \mu 1$ of elution buffer was added, centrifuged at $10000 \mathrm{rpm}$ for 1 minute and the eluted viral RNA was kept at $-80^{\circ} \mathrm{C}$ until use. 
Table 1 RT-PCR and Nested-PCR oligonucleotide primers

\begin{tabular}{|c|c|c|c|}
\hline Serotype & primer & Sequence $5^{\prime}-3^{\prime}$ & Size in bp \\
\hline \multirow{5}{*}{1,3 and 4} & D1 & TCAATATGCTGAAACGCGCGAGAAACCG & 511 \\
\hline & D2 & TTGCACCAACAGTCAATGTCTTCAGGTTC & 511 \\
\hline & TS1 & CGTCTCAGTGATCCGGGGG & $482(\mathrm{Dl}$ and $\mathrm{TS} 1)$ \\
\hline & TS3 & TAACATCATCATGAGACAGAGC & $290(\mathrm{Dl}$ and TS3) \\
\hline & TS4 & CTCTGTTGTCTTAAACAAGAGA & $392(\mathrm{Dl}$ and TS4) \\
\hline \multirow{2}{*}{2} & DV1 & GGRACKTCAGGWTCTCC & \multirow{2}{*}{362} \\
\hline & DSP2 & CCG GTGTGCTCRGCYCTGAT & \\
\hline
\end{tabular}

2.5 Reverse Transcriptase Polymerase Chain Reaction (RTPCR)

In the current study, all the sera samples were screened by RTPCR with dengue virus group-specific consensus primer pairs for the presence of dengue virus RNA. RT-PCR and the conventional nested PCR were performed according to the previous protocol (Lanciotti et al., 1992) with some modifications. The viral RNA was amplified using DENV consensus primers and serotypespecific primers (Table 1). Briefly, in $50 \mu$ final volume reaction mixture containing $10 \mu \mathrm{l}$ of AMV/Tfl 5X Reaction Buffer, $1 \mu 1$ of dNTP Mix (10mM each dNTP, final concentration $0.2 \mathrm{mM}), 2 \mu 1$ of $25 \mathrm{mM} \mathrm{MgSO}$ (final concentration $1 \mathrm{mM}$ ), $1 \mu \mathrm{l}$ of $\mathrm{AMV}$ Reverse Transcriptase $5 \mathrm{U} / \mu \mathrm{l}$ (final concentration $0.1 \mathrm{U} / \mu \mathrm{l}$ ), $1 \mu 1$ of Tfl DNA Polymerase (final concentration $5 \mathrm{U} / \mu \mathrm{l}$ ), 50 pmol (final concentration $1 \mu \mathrm{M}$ ) of each forward (D1) and reverse (D2) primers (Table 1), $5 \mu$ l of purified viral RNA and nuclease free water was added to make total volume $50 \mu$ l. The RT-PCR temperature cycling conditions involved: Incubation for 1 hour at $42^{\circ} \mathrm{C}$, initial denaturation at $\left(94^{\circ} \mathrm{C}, 3 \mathrm{~min}\right), 35$ cycle of denaturation $\left(94^{\circ} \mathrm{C}, 30\right.$ second $)$, primers annealing $\left(55^{\circ} \mathrm{C}, 1\right.$ minute), primer extension $\left(72^{\circ} \mathrm{C}, 2\right.$ minutes $)$ and final extension at $72^{\circ} \mathrm{C}$ for 5 minutes.

\subsection{Serotyping}

Under the same above mentioned temperature cycling condition, $1.0 \mu \mathrm{l}$ of the above RT-PCR product (1:10 in sterile distilled water) was added as a template in the subsequent nested PCR reaction to $50 \mu \mathrm{l}$ reaction volume mixture containing forward primer D1 and type-specific (TS) reverse primers: TS1, TS3 and TS4 reverse primers for serotype 1, 3 and 4, and forward primer DV1 and DSP2 reveres primers for serotype 2 (Table 1) and was further amplified by nested PCR step (second round). The PCR products amplification was analysed on gel electrophoresis (1.5 agarose in $1 \mathrm{X}$ Tris-Acetate EDTA buffer) and gel was stained with $1 \%$ ethidium bromide and the size compared with a $1 \mathrm{~Kb}$ plus DNA ladder (Invitrogen TM, catalogue number 10787018) using Gel Doc XR Imaging System (Bio-Rad).

\subsection{Sequencing and bioinformatics analysis}

RT-PCR products $(480,362 \mathrm{bp})$ of $12 \mathrm{DENV}$ positive samples were purified and were sequenced by the Macrogen Company (Seoul, Korea). The sequences similarities were done following the previous method (Altschul et al., 1997) and compared to reference sequences of Dengue serotypes detected in BLAST and downloaded from GenBank (www.ncbi.nlm.nih.gov/genbank/). Similarity tree was obtained from database online by phylogeny.fr (http://www.phylogeny.fr/).

\section{Results}

\subsection{RT-PCR}

RT-PCR detected $79(64.2 \%)$ DENV positive samples and 44 (35.8\%) negative out of 123 febrile illness human subjects tested samples. The results of $1.5 \%$ agarose electrophoresis analysis of RT-PCR and nested PCR products were demonstrated in the figure $(1,2)$ respectively. The RT-PCR detected 79 positive samples, 63 out of these samples are DENV1, 13 DENV2 and 3 concurrent mixed infections with (DENV1, DENV2), on the other hand DENV3 and DENV4 were not detected in all tested samples.

\subsection{Sequencing}

Dengue virus RNA from 12 RT-PCR positive blood samples was extracted, purified, its concentration was tested using Nano photometer (2000C; Thermo Scientific, Waltham, MA, USA), sequenced by Macrogen Company (Seoul, Korea) and the sequencing reactions were performed using MJ Research PTC225 Peltier Thermal Cycler. The two DENV serotypes (DENV1 and DENV2) detected by RT-PCR were further sequenced and their partial E gene sequences were directly determined from the selected samples in the current study. 

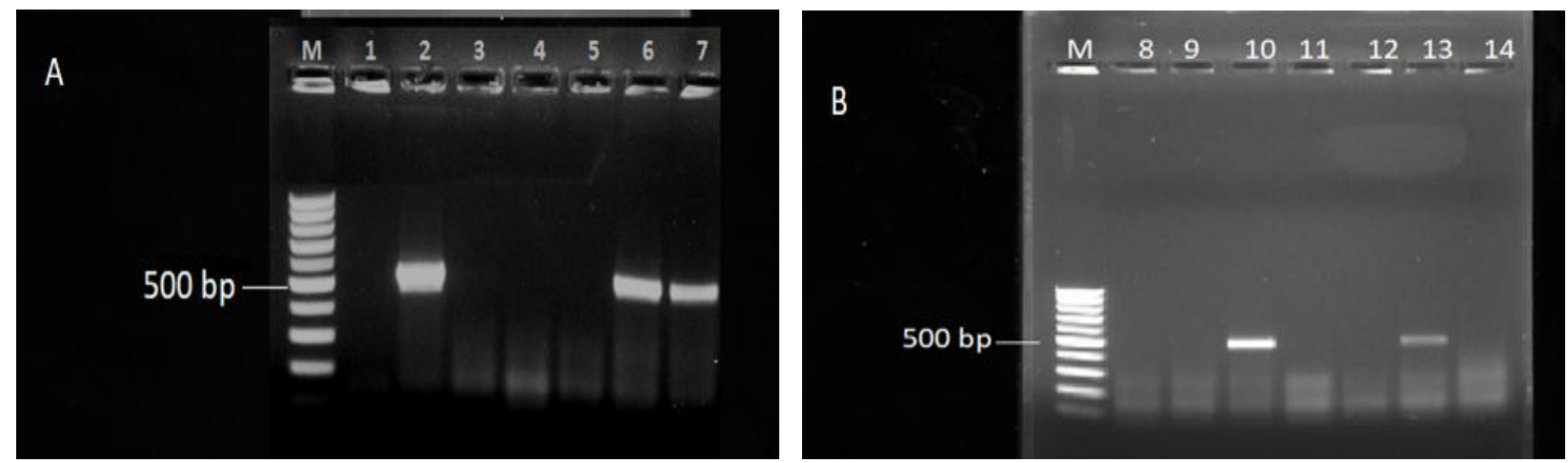

Figure 1 (A, B) Agarose gel images showing the separation of amplified DNA by RT-PCR using DENV1 specific primer sets. Lane M, standard size marker, L1 negative control, L2 positive control (DENV1/500 bp), L 3-14 test samples

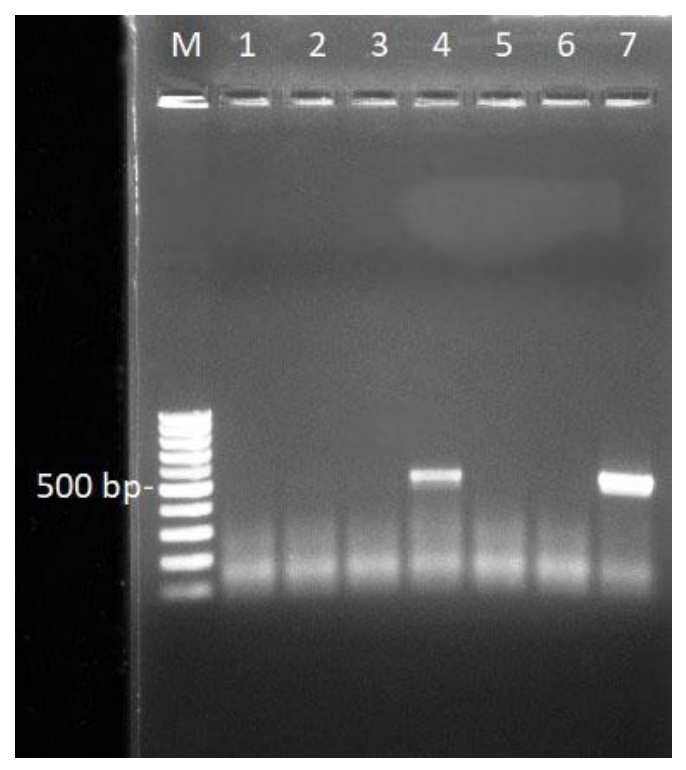

Figure 2 Agarose gel images showing the separation of amplified DNA by nested PCR using DENV1 specific primer sets. Lane ${ }_{\mathrm{M}}$, standard size marker, $\mathrm{L}_{6}$ negative control, $\mathrm{L}_{7}$ positive control (DENV1/500 bp), $\mathrm{L}_{1-5}$ test samples

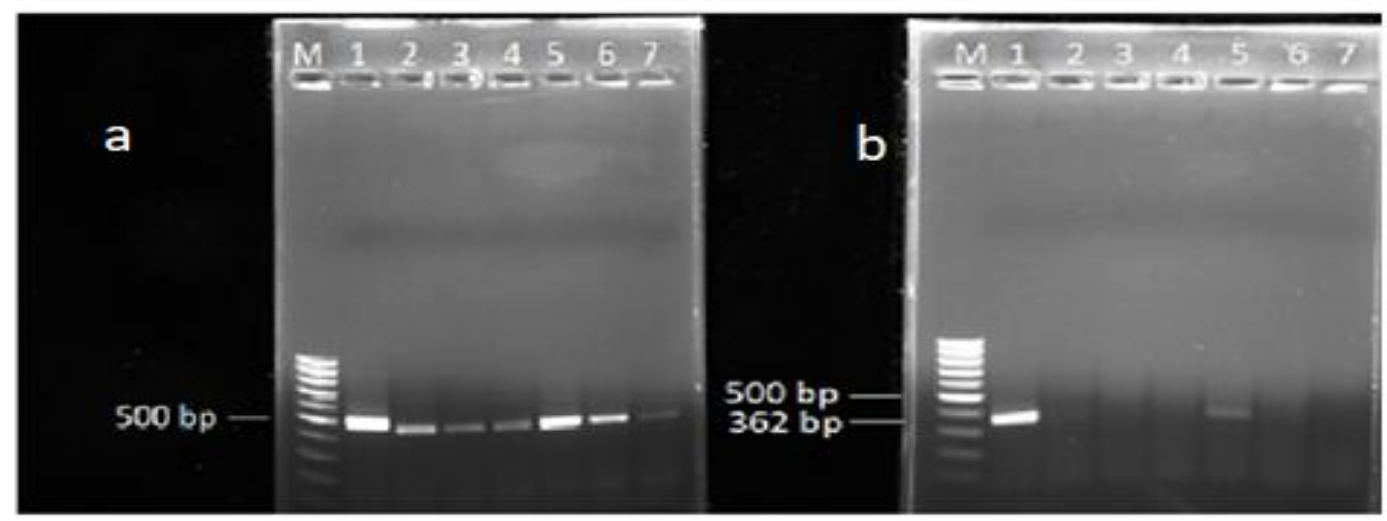

Figure 3 Agarose gel images showing the separation of amplified DNA (a) dengue virus serotype1 (500 bp) and (b) dengue serotype2 (362 bp) by RTPCR using dengue serotype specific primer sets. Lane ${ }_{M}$, standard size marker, $L_{1}$ positive control, $L_{2-7}$ test samples

Journal of Experimental Biology and Agricultural Sciences http://www.jebas.org 


\subsection{Phylogenetic analysis}

Complete and partial envelope genome sequences from DENV1 and DENV2 were isolated and identified in this study. The sequences were searched for sequence similarity through BLAST (www.ncbi.nlm.nih.gov/BLAST/) and compared to reference sequences of Dengue serotypes detected in BLAST and downloaded from GenBank (www.ncbi.nlm.nih.gov/genbank/). Complete genome sequences of DENV1 was 97\% (462/476) similar to isolate from Eritrea and Taiwan (sequence ID: KU509258. 1Length: 10377 Number of Matches) and DENV2 sequence was 99\% (460/464) similar to isolate from Sudan and India sequence ID: JN935394. 1Length: 486 number of Matches. From dengue serotype 1 and serotype 2 sequences were correlated to the sequences available in GenBank and their generated phylogenetic similarity trees were respectively shown in figure $(4,5)$.

\section{Discussion}

Dengue is an important emerging disease of the tropical and subtropical regions (Bhatt et al., 2013). It is a complex disease whose symptoms are difficult to distinguish from other common febrile illnesses and can progress from a mild, non-specific viral disease to irreversible shock and death within a few hours. This makes the differential diagnosis problematic especially in the Jazan area, where there is a high incidence of febrile illnesses. Total of 123 blood samples from acute febrile illness subjects all (age, sex and nationality) during their first hospital admission to 13 hospitals at Jazan area were collected. All sera were subjected to reverse transcriptase polymerase chain reaction (RT-PCR) and nested PCR. Dengue virus RNA from 12 RT-PCR positive blood samples was extracted, purified, sequenced and their nucleotide sequences were searched for similarity in the gen-bank. The molecular serotyping of RT-PCR positive samples $(\mathrm{n}=79)$ revealed DENV1 (63/79), DENV2 (13/79) and (3/79) concurrent mixed infection with (DENV1, DENV2) using dengue serotype1 (480 bp) and serotype 2 (362 bp) specific primer sets, on the other hand DENV3 and DENV4 were not detected in all collected blood samples. During 2008, the same dengue serotypes (serotype 1 and 2) was first reported from Al-Madinah, Saudi Arabia (El-Badry et al., 2014) But Fakeeh \& Zaki (2003) and Organji et al. (2017) reported three dengue serotypes (DEN 1, 2 and 3) in Jeddah.

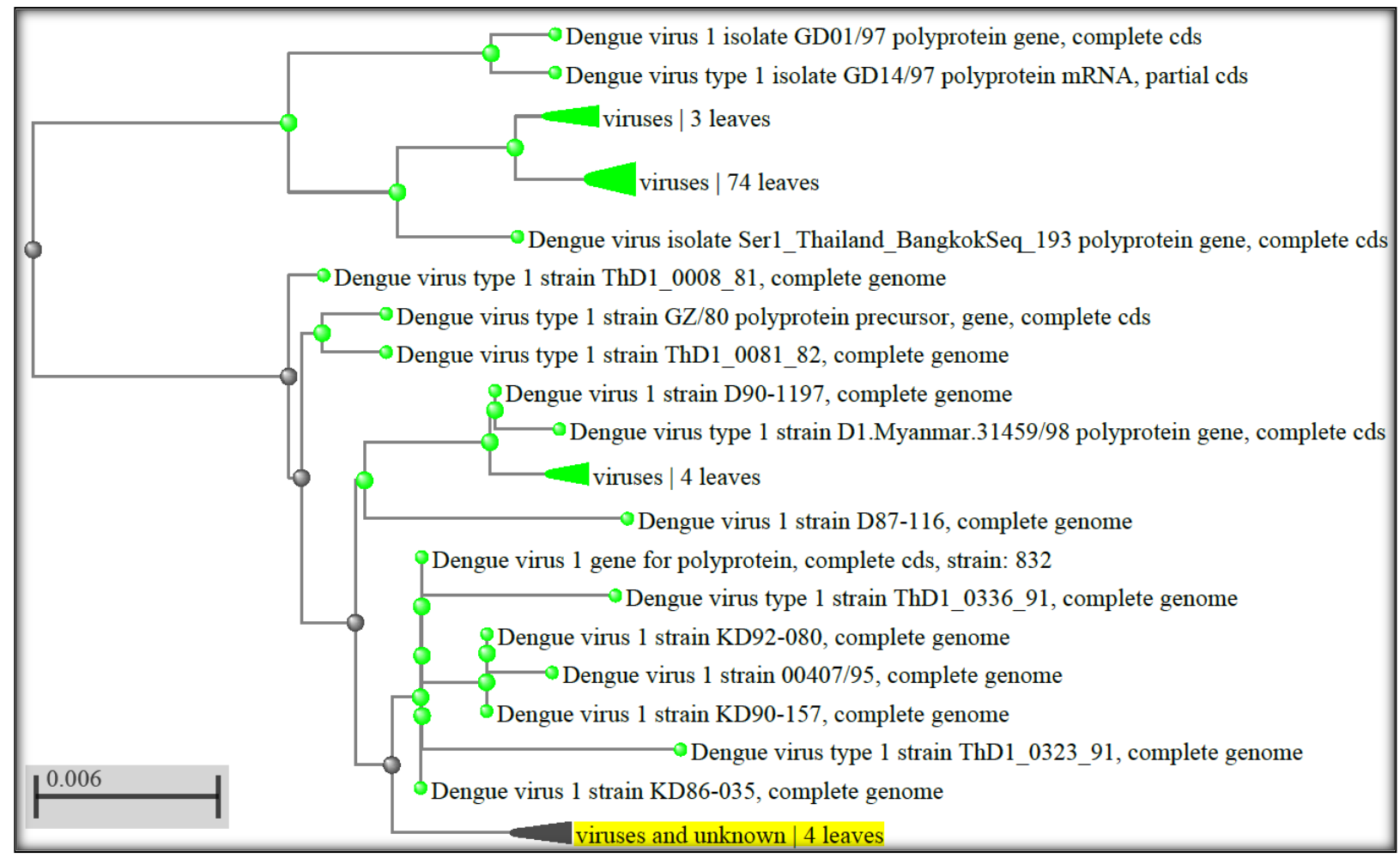

Figure 4 Phylogenic relationships between DENV1 isolated from febrile illness patient at Jazan area, KSA with other established DENV1 relevant serotypes. The MrBayes V.3.2 software is used to analyse the phylogenetic similarity tree. Only values above $90 \%$ of similarities were shown in this illustrated figure.

Journal of Experimental Biology and Agricultural Sciences

http://www.jebas.org 


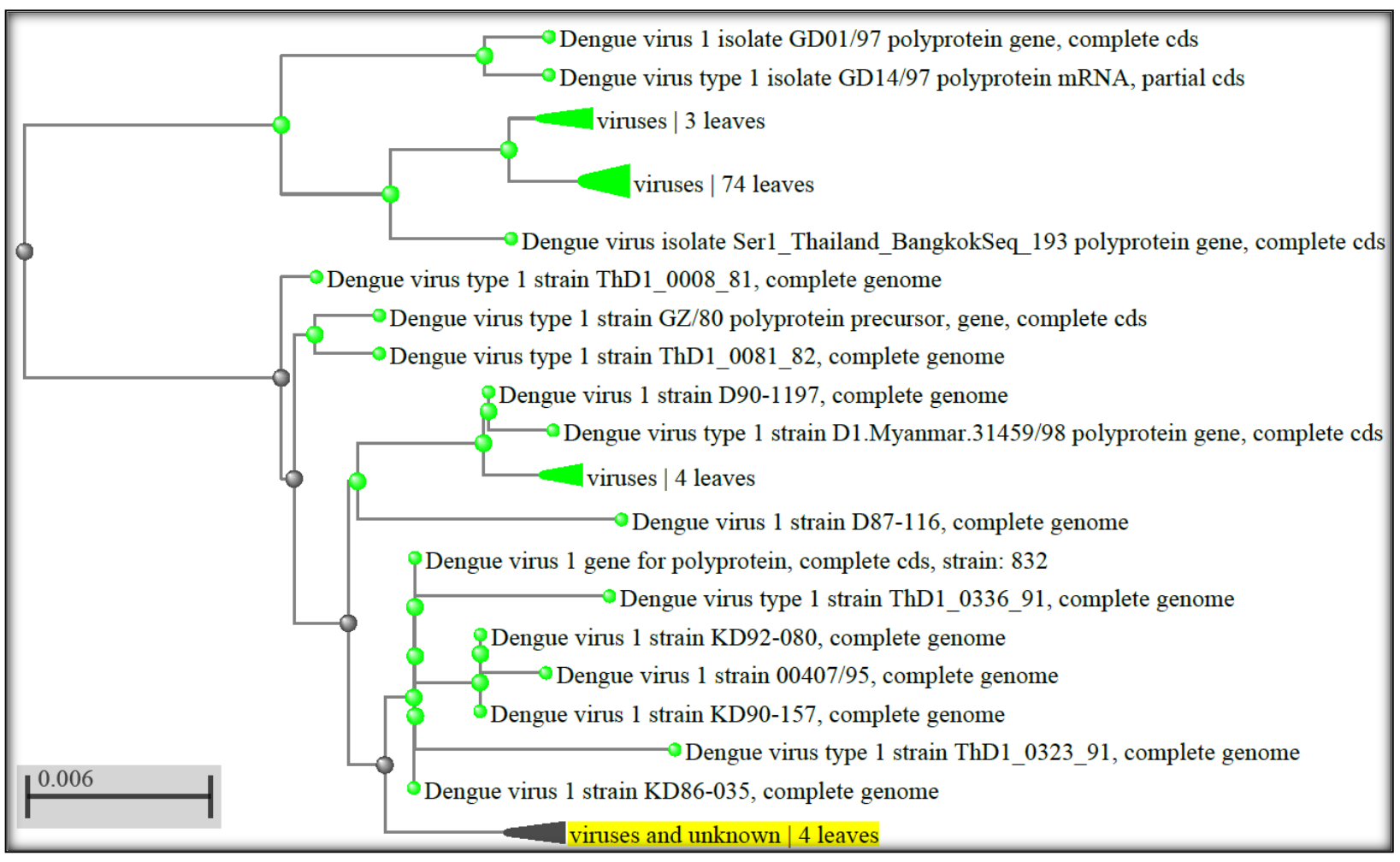

Figure 4 Phylogenic relationships between DENV1 isolated from febrile illness patient at Jazan area, KSA with other established DENV1 relevant serotypes. The MrBayes V.3.2 software is used to analyse the phylogenetic similarity tree. Only values above $90 \%$ of similarities were shown in this illustrated figure.

Therefore, we established dengue serotype1 and serotype2 as the dominant serotypes currently circulating in Jazan area for the first time. Globally, over the last five decades, dengue has emerged as a real critical threat to population health in most country included Saudi Arabia (El-Badry et al., 2014). The World Health Organization estimates that 50 to 100 million dengue infections occur annually half the world's population lives in countries where dengue is endemic (Guzman et al., 2010). The four dengue virus types (1-4), called dengue virus serotypes, form a phylogenetic group and differ in nucleotide sequence from each other. These are closely related to one another rather than to other flaviviruses and form an antigenic complex of their own.

Complete and partial envelope genome sequences from serotype 1 and serotype 2 were isolated and identified. The sequences was searched for sequence similarity through BLAST (www.ncbi.nlm.nih.gov/BLAST/) and compared to reference sequences of Dengue serotypes detected in BLAST and downloaded from GenBank (www.ncbi.nlm.nih.gov/genbank/). Complete genome sequences of DENV1 was 97\% (462/476) similar to isolate from Eritrea and Taiwan (Shihada et al., 2017) and DENV2 sequence was 99\% (460/464) similar to isolate from Sudan and India (Kumar et al., 2013). From dengue serotype 1 and serotype 2 sequences were correlated to the sequences available in GenBank and their generated phylogenetic similarity trees were shown. Concurrent mixed infection with multiple DENV serotypes (DENV1, DENV2 was detected in three patients; one of them expired during hospitalization and treatment. Our result was consistent with a prospective observational study that conducted among adults dengue patients hospitalized in Bangkok (Thanachartwet et al., 2016).

\section{Conclusion}

Concurrent mixed infection with multiple DENV serotypes (DENV1, DENV2 was detected in three patients; one of them was expired during the hospitalization and treatment. This finding is considered as alarm signs of the large dispersal of different DENV serotypes. Therefore, prevising a disaster situation could be expected in Jazan area. However, this observation should be warning to health authorities for control measures. We recommended that all febrile illness patients should be tested for dengue antibodies and clinicians/physicians consider the possibility of dengue cases when dealing with febrile patients. Epidemiological studies of dengue infections in Jazan areas are required. 


\section{Acknowledgements}

A.M. Hakami and M.I. Qadri are supported by King Abdulaziz City for Science and Technology (KACST). The authors acknowledge the Microbiology Department, Central Laboratory, King Fahd Hospital, Jazan, Saudi Arabia for technical assistance and molecular laboratories facilities.

\section{Conflict of interests}

The authors declare no competing interests and contribute equally.

\section{References}

Alto BW, Juliano SA (2001) Precipitation and temperature effects on populations of Aedes albopictus (Diptera: Culicidae): implications for range expansion. Journal of Medical Entomology 38: 646-656.

Altschul SF, Madden TL, Schäffer AA, Zhang J, Zhang Z, Miller W, Lipman D J (1997) Gapped BLAST and PSI-BLAST: a new generation of protein database search programs. Nucleic Acids Research 25: 3389-3402.

Armstrong PM, Rico-Hesse R (2003) Efficiency of dengue serotype 2 virus strains to infect and disseminate in Aedes aegypti. American Journal of Tropical Medicine and Hygiene 68: 539-544.

Ashshi AM (2015) Serodetection of Dengue virus and its antibodies among blood donors in the western region of Saudi Arabia: a preliminary study. Blood Transfusion 13: 135-138.

Ashshi AM (2017) The prevalence of dengue virus serotypes in asymptomatic blood donors reveals the emergence of serotype 4 in Saudi Arabia. Virology Journal 14: 107-114.

Azhar EI, Hashem AM, El-Kafrawy SA, Abol-Ela S, Abd-Alla AM, Sohrab SS, Madani TA (2015) Complete genome sequencing and phylogenetic analysis of dengue type 1 virus isolated from Jeddah, Saudi Arabia. Virology Journal 12: 1-11.

Bhatt S, Gething PW, Brady OJ, Messina JP, Farlow AW, Moyes CL, Drake JM, Brownstein JS, Hoen AG, Sankoh O, Myers MF (2013) The global distribution and burden of dengue. Nature 496: 504-507.

Chan M, Johansson MA (2012) The incubation periods of dengue viruses. PloS one 7: e50972.

de Alwis R, Beltramello M, Messer WB, Sukupolvi-Petty S, Wahala WM, Kraus A, Wang WK (2011) In-depth analysis of the antibody response of individuals exposed to primary dengue virus infection. PLoS Neglected Tropical Diseases 5: e1188.
Dhanoa A, Hassan SS, Ngim CF, Lau C, Chan TS, Adnan NAA, Rajasekaram G (2016) Impact of dengue virus (DENV) coinfection on clinical manifestations, disease severity and laboratory parameters. BMC Infectious Diseases 16: 406-619.

El-Badry AA, El-Beshbishy HA, Al-Ali KH, Al-Hejin AM, ElSayed WSM (2014) Molecular and seroprevalence of imported dengue virus infection in Al-Madinah, Saudi Arabia. Comparative Clinical Pathology 23: 861-8.

Fakeeh M, Zaki AM (2003) Dengue in Jaddah. Saudi Arabia, 1994-2002. Dengue Bulletin 27: 13-18.

Gubler DJ (2002) Epidemic dengue/dengue hemorrhagic fever as a public health, social and economic problem in the 21st century. Trends in microbiology 10: 100-103.

Guzman MG, Halstead SB, Artsob H, Buchy P, Farrar J, Gubler DJ, Nathan MB (2010) Dengue: a continuing global threat. Nature Reviews Microbiology 8: S7-S16.

Kumar NP, Jayakumar PR, George K, Kamaraj T, Krishnamoorthy K, Sabesan S, Jambulingam P (2013) Genetic characterization of dengue viruses prevalent in Kerala State, India. Journal of Medical Microbiology 62: 545-552.

Lambrechts L, Scott TW, Gubler DJ (2010) Consequences of the expanding global distribution of Aedes albopictus for dengue virus transmission. PLoS Neglected Tropical Diseases 4: e646.

Lanciotti RS, Calisher CH, Gubler DJ, Chang GJ, Vorndam AV (1992) Rapid detection and typing of dengue viruses from clinical samples by using reverse transcriptase-polymerase chain reaction. Journal of Clinical Microbiology 30: 545-551.

Martins CA, de Souza BM, Ramasawmy R, de Figueiredo RP, Gimaque JBL, Braga WSM, Nogueira ML, Nozawa S, Naveca FG, Figueiredo LTM, Mourão MPG (2014) Clinical and virological descriptive study in the 2011 outbreak of dengue in the Amazonas, Brazil. PLoS One, 9: e100535.

Organji SR, Abulreesh HH, Osman GE (2017) Circulation of dengue virus serotypes in the city of Makkah, Saudi Arabia, as determined by reverse transcription polymerase chain reaction. Canadian Journal of Infectious Diseases and Medical Microbiology 16: 5-9.

Reddy MN, Dungdung R, Valliyott L, Pilankatta R (2017) Occurrence of concurrent infections with multiple serotypes of dengue viruses during 2013_2015 in northern Kerala, India. Peer Journal 5:.2970-2985

Shihada S, Emmerich P, Thome-Bolduan C, Jansen S, Gunther S, Frank C, Schmidt-Chanasit J, Cadar D (2017) Genetic Diversity 
and New Lineages of Dengue Virus Serotypes 3 and 4 in Returning Travelers, Germany, 2006-2015. Emerging Infectious Disseise 23: 272-275.

Simard F, Nchoutpouen E, Toto JC, Fontenille D (2005) Geographic distribution and breeding site preference of Aedes albopictus and Aedes aegypti (Diptera: Culicidae) in Cameroon, Central Africa. Journal of Medical Entomology 42: 726-731.

Thanachartwet V, Varunee D, Duangjai S, Akanitt J, Nittha O, Sathaporn O, Manoon S, Anan W (2016) Serum procalcitonin and peripheral venous lactate for predicting dengue shock and/or organ failure: a prospective observational study. PLoS Neglected Rropical Diseases 10: e0004961.
Varatharaj A (2010) Encephalitis in the clinical spectrum of dengue infection. Neurology India 58: 585-591.

Vinodkumar CS, Kalapannavar NK, Basavarajappa KG, Sanjay D, Gowli C, Nadig NG, Prasad BS (2013) Episode of coexisting infections with multiple dengue virus serotypes in central Karnataka, India. Journal of infection and public health, 6: 302-306.

Whitehead SS, Blaney JE, Durbin AP, Murphy BR (2007) Prospects for a dengue virus vaccine. Nature Reviews Microbiology 5: 518-528.

World Health Organization (2014) Dengue and severe dengue. World Health Organization, Geneva. 